https://doi.org/10.32735/S0718-2201202000050781

$37-49$

\title{
LA IGLESIA COMO APARATO IDEOLÓGICO EN LAS REPRESENTACIONES SOCIALES DE JUAN MONTALVO: UN ANÁLISIS DEL DESENLACE DE SU QUIJOTE
}

The Church as an ideological system in the social representations of Juan Montalvo: an analysis of his Quijote's ending

\author{
JOHN O'KUINGHTTONS RODRÍGUEZ \\ Universidad de São Paulo (Brasil) \\ johnochile@gmail.com.br
}

\section{Resumen}

En este trabajo analizamos la representación de la Iglesia como aparato ideológico en el desenlace de la novela Capítulos que se le olvidaron a Cervantes, del autor ecuatoriano Juan Montalvo. Nos concentramos en su final, pues entendemos que dicha parte resume las principales representaciones del autor vinculadas a esta institución. El análisis será complementado con una contextualización del origen de la novela y de las premisas ideológicas centrales de Montalvo, apoyándonos en remisiones a algunos de sus trabajos ensayísticos. Asimismo, comentaremos las repercusiones que dichas representaciones tuvieron en la formalización de los dos personajes medulares de su novela. Para atender a estos propósitos, seguiremos los conceptos teóricos de Aparatos Ideológicos del Estado (AIE) según Althusser (2013) y de Ideología y Representaciones Sociales conforme van Djik (1999).

Palabras clave: Quijote; Ideología; Representaciones Sociales; Iglesia; Aparatos Ideológicos del Estado

\section{Abstract}

This paper aims to analyse the representation of the Church as an ideological system that can be found in the end of the only novel written by the Equadorian writer Juan Montalvo - Capítulos que se le olvidaron a Cervantes - considering that this part of the book summarizes, in a brief and synthetic way, the main orientations of his social beliefs about the constitution of the Catholic church and its members. The analysis will be based on a contextualization of the origin of the novel and on Montalvo's main ideological premises, according to some of his essays. Likewise, I will comment the effects that these ideological foundations carried to the conformation of the central characters of the novel. The study is based on the concept of Ideological Systems of the State conceived by Althusser (2013) and the idea of Ideology and Social Representations designed by van Djik (1991).

Key word: Quixote; Ideology; Social Representations; Church; Ideological Systems of the State. 


\section{INTRODUCCIÓN}

\section{EL QUIJOTE MONTALVINO Y LA IGLESIA}

En una de las líneas del Buscapié, el fecundo prólogo que da entrada a su Quijote, Juan Montalvo se pregunta "¿Qué pudiera proponerse, me dirán, el que hoy escribiera un Quijote bueno o malo?" (Montalvo, 2004, p. 90). Consciente de la responsabilidad artística que significa continuar el ciclo narrativo ${ }^{1}$ inaugurado por Cervantes, Montalvo declara que un escritor solo puede imitar el Quijote, jamás competir con él ${ }^{2}$. Por ello, se abstuvo de medir su trabajo con el de su antecedente sugiriendo, en cambio, que el material cervantino le habría de servir de sustrato para transmitir algunas de sus representaciones sociales ${ }^{3}$ personales en torno al poder político, religioso y a la moral ${ }^{4}$.

En lo que concierne estrictamente a las representaciones religiosas, importa subrayar que Montalvo defendía la vida trascendental y la recompensa por las obras. No

\footnotetext{
${ }^{1}$ Entenderemos ciclo "como un conjunto textual múltiple que narra y continúa una misma historia que ocurre dentro de un universo o mundo narrativo común". Un ciclo conlleva ciertos trazos narrativos como "la amplitud, la unidad cronológica y temática, y los vínculos intertextuales, tanto implícitos como explícitos, entre las distintas partes del conjunto textual"' (Gutiérrez Trápaga, 2016, p. 138).

${ }^{2}$ Otras continuaciones son, por ejemplo, Semblanzas caballerescas o las nuevas aventuras de don Quijote de la Mancha, 1886, de Luis Otero Pimentel, o Don Quijote en América o sea la cuarta salida del ingenioso hidalgo de La Mancha, 1905, de Tulio Febres Cordero. "En esta versión indiana, muy particular al cabo por las intenciones que escondía el ejercicio de Febres, el heredero de don Quijote aparece recorriendo los Andes venezolanos convertido esta vez en un defensor del progreso y la modernidad, porque su "patria está donde hay tinieblas que disipar, multitudes irredentas que instruir y campos sin cultivo donde aventar la fúlgida simiente del modernismo redentriz" (Aguilar, 2017,pp. 19-20)

${ }^{3}$ Respecto de la ideología, Žižek advierte que esta "puede designar cualquier cosa, desde una actitud contemplativa que desconoce su dependencia en relación a la realidad social, hasta un conjunto de creencias dirigido a la acción" (Trad. del autor) (Žižek, 2013, p. 9). Para García Astrada es "un sistema de ideas que pretende no sólo una global interpretación del mundo, presentándose como una cosmovisión total, sino también su transformación y el ponerlo al servicio de un poder determinado" (García Astrada, 1971, p. 14). Riorda y Farré sostienen que es "el conjunto integrado de teorías, reivindicaciones y propuestas que constituyen un programa socio político." (Riorda \& Farré, 2012, p. 38). Este estudio se apoyará en Van Dijk, quien entiende ideología como: "la base de las representaciones sociales compartidas por los miembros de un grupo" (Van Dijk, 1999, p. 21).

${ }^{4}$ Para relacionar poder e ideología recurrimos al concepto de Aparatos Ideológicos del Estado (AIE), de Althusser, definidos como "un cierto número de realidades que se presentan al observador inmediato bajo la forma de instituciones distintas y especializadas" (Trad. del autor) (Althusser, 2013, p. 114). Los AIEs pueden ser religiosos, escolares, familiares, jurídicos, políticos y culturales y se diferencian de los Aparatos Represivos del Estado (ARE), cuya acción se da por medio de la violencia. En el período precapitalista, el AIE dominante era la Iglesia, que absorbía tanto las funciones religiosas como las escolares, al tiempo que controlaba la difusión de la información y la cultura. Para efectos operativos, utilizaremos de preferencia las siglas AIE y ARE.

38 | Alpha No50 (Julio 2020) PÁGs. 37-49. ISSN 07 16-4254
} 
obstante, como comenta Ángel Esteban (Montalvo, 2004), sus creencias no siempre se vertieron en una escritura cohesionada, sino en un estilo más bien caótico. Enrique Anderson Imbert (1957) no discrepa de este juicio y agrega que las asimetrías o el desorden en que incurre Montalvo se explican por el hecho de que su Quijote es la obra de un ensayista antes que la de un narrador, la "novela de un militante político", en palabras de Jácome Clavijo (Clavijo, 2007, p. 66). Sus capítulos, resume Anderson Imbert, ahondan en el examen de las virtudes y en el ejercicio de una prosa imbuida en el Siglo de Oro español, de tal modo que al leerlos deparamos con una obra de acento renacentista concebida en el umbral del siglo XX. A lo anterior hay que añadir que su vindicación de un sistema moral coherente de fundamento religioso no entroncaba necesariamente con la defensa del modelo institucional promovido por la Iglesia católica, aún dominante en el concierto de creencias de la América postcolonial. Más aún, la posición ideológica liberal y humanista llevó a Montalvo a sostener enconadas disputas con el poder eclesiástico y a dirigir agudas reconvenciones al modo como esta se articulaba en la vida social. Estos acercamientos y distancias en cuanto a la base institucional y doctrinal de la Iglesia dejaron una huella de ambivalencia en su escritura. Ejemplo de ello son las complejas remisiones al tema eclesial que hallamos en el desenlace de su Quijote y que en este estudio pretendemos mostrar.

\section{INTERPRETACIÓN Y ANÁLISIS}

\section{EL PENSAMIENTO DE MONTALVO: REPRESENTACIONES SOCIALES Y LOS AIE}

Montalvo tuvo siempre conciencia de la inestabilidad económica y social del Ecuador emancipado y para su mejoramiento vislumbró la necesidad de una articulación afinada entre los estamentos civil, militar y eclesiástico ${ }^{5}$ mediante aparatos ideológicos debidamente proporcionales cuanto al número de sus componentes.

En términos reduccionistas, porque la realidad empírica de las expresiones ideológicas es mucho más compleja, podríamos afirmar que los sistemas de representaciones sociales postcoloniales en América se remitieron fundamentalmente a:

\footnotetext{
${ }^{5}$ Como adelantamos, Althusser define estos estamentos como Aparatos Ideológicos del Estado, distinto en cuanto a objetivos a los denominados Aparatos Represivos del Estado. Tomando en cuenta esta bipartición, se advierte que Montalvo remitirá la Iglesia al grupo de instituciones de influyente base ideológica. Por ello sustentará esta crítica concreta en el orden moral.
} 
a) Una posición conservadora, que defiende y promueve las directrices coloniales, tanto en la constitución de los poderes como en la noción de lengua ${ }^{6}$ y cultura.

b) Una posición liberal, centrada en la integración y el dinamismo sociales ${ }^{7}$.

Por ello, a causa de su filiación liberal, y aun reconociendo la necesidad del aparato eclesiástico en la configuración de la sociedad, Montalvo veía en parte importante del clero lo opuesto a sus premisas ideológicas debido a los acentos conservadores y aristócratas que advertía entre muchos de sus integrantes.

Como enseña Naranjo (Montalvo, 2006), el liberalismo del autor no fue incompatible con el romanticismo ni con el neoclasicismo que profesó. Para Roig, el valor de las ideas sociales americanas defendidas por Montalvo no reside en su posible "socialismo", sino "en una línea liberal progresista en la medida en que su pensamiento estuvo condicionado por las exigencias de emergencia social de las clases medias, lógicamente con las contradicciones que esto mismo supone" (Roig, 1995, p. 27).

Sus representaciones sociales poseen, pues, huella positivista y romántica. Para el ecuatoriano, la política se afinca en la moral trascendente y su romanticismo se transmite mediante lo que Roig denominó conciencia social, cuyo signo es la defensa de la libertad, la que, por su parte, se divide en tres campos complementarios: libertad natural, libertad personal y libertad política. Montalvo asumió la noción de libertad y de justicia social propia de los ajustes políticos decimonónicos en América Latina. Su denuncia de la esclavitud, el colonialismo, la ignorancia, la corrupción y la miseria fue congénere con su concepto de civilización. Su entendimiento de libertad, propiedad, trabajo y cuerpo social explican, por ejemplo, la idea de que la caridad es obligación moral del buen ciudadano o de que a la mujer le competen únicamente las faenas domésticas. Roig no reconoce contradicción en estas representaciones, sino "un desesperado esfuerzo de autoafirmación, y la expresión de un grupo social emergente, con todos sus temores, sus desconfianzas, sus odios y sus esperanzas y también, lógicamente, sus derechos" (Roig, 1995, p. 78). Su lectura de la realidad social, añade, es consecuencia de su época, no de

\footnotetext{
${ }^{6}$ Los conservadores postulan la idea de lengua pura, que identifican con los parámetros provenientes de la península. En el caso de Montalvo, esta depuración de la lengua se identifica con la moral, que, como apunta Plutarco Naranjo (2006), no se relaciona unívocamente con el cristianismo.

${ }^{7}$ González Stephan (1987) ha sintetizado los postulados centrales de la ideología liberal centrándolos en: la reforma del aparataje estatal, la bipartición de los poderes, la igualdad formal ante la ley, la libertad individual y la libre competencia, entre otros.

40 | Alpha No50 (Julio 2020) PÁGs. 37-49. ISSN 07 16-4254
} 
una deficiencia de los análisis que llevó a cabo. Las representaciones sociales, vale subrayar, son siempre hijas de su tiempo ${ }^{8}$.

\section{LOS AIE ENEL DESENLACE DEL QUIJOTE AMERICANO}

$\mathrm{Al}$ revisar el desenlace del Quijote ecuatoriano, tienta suponer que su autor imaginó un punto intermedio entre los respectivos finales de las novelas de Cervantes y Avellaneda debido a dos resoluciones cardinales:

a) Don Quijote no muere (como en Avellaneda);

b) Su héroe elabora un testamento (como en Cervantes).

No obstante, esta precipitada presunción entrampa en el hecho de que Montalvo no solo no apreciaba la conducción literaria del Quijote de 1614 y su manejo de la risa y de la burla, sino que denunciaba el oportunismo y la pretensión de que su autor se hubiera atrevido a medirse con Cervantes, según expone en el sexto capítulo del Buscapié. Esta razón torna altamente improbable la eventualidad de que Montalvo haya extraído de Avellaneda la decisión de perpetuar a su héroe ${ }^{9}$. Más razonable parece ser, en cambio, la gravitación de Cervantes con la redacción de un testamento. Sin embargo, a diferencia de su admirado antecesor (y también del repudiado epígono), Montalvo insistirá en un aspecto que es necesario hacer constar: la sorna ideológica contra los malos clérigos. Para entender esta ojeriza y sus implicaciones dentro de los $\mathrm{AIE}^{10}$ conviene revisar la composición del ambiente final de su ficción.

\footnotetext{
${ }^{8}$ Respecto de la noción de idea y de la movilidad temporal de las ideologías, Van Dijk recuerda que estas últimas tradicionalmente han sido comprendidas como sistemas de ideas socialmente compartidas. Asimismo, advierte que el concepto de idea, aun cuando pueda ser metodológicamente operativo, es vago y que por ello propone su reemplazo por el concepto de creencia, en el que se inscriben todos los productos del pensar. Muchas creencias se van modificando por medio de la práctica social, la interacción con otros individuos o el discurso. Las ideologías, por su parte, también pueden cambiar, pero para ello se necesita tiempo debido a su condición inherentemente social y compartida.

${ }^{9}$ A propósito de esta decisión, es admisible complementar que Montalvo conocía bien los tópicos que regían la composición de los libros de caballerías. Del mismo modo que Cervantes en la conclusión de la primera parte y Avellaneda en su respectivo final, el ecuatoriano deja abierto la eventualidad de una continuación.

${ }^{10} \mathrm{Al}$ tratar la cuestión de la Iglesia como aparato ideológico, Althusser sostiene que en el período precapitalista el AIE dominante era precisamente dicha institución, que absorbía tanto las funciones religiosas como las escolares, al tiempo que controlaba la difusión de la información y la cultura. La lucha anticlerical, vale decir, contra uno de los componentes de ese AIE concreto, se convertirá en una de las consignas centrales de la actividad pública y artística de Montalvo.
}

AlPHA No 50 (JULIO 2020) PÁGS. 37-49. ISSN 07 16-4254| 41 


\subsection{EL PENÚLTIMO CAPÍTULO}

El desenlace comienza a prefigurarse en el momento en que Sancho le propone a su amo la posibilidad de retornar definitivamente a la aldea: " $i S i$ diésemos por concluidas nuestras aventuras, señor, y tornásemos a nuestro pueblo a vivir como hombres de bien y buenos cristianos?" (Montalvo, 2004, p. 493). Este pedido, sin embargo, no solo es cuestionado por el caballero, sino que, además, sirve de pretexto para introducir una lúcida digresión acerca de la poesía. Una breve alusión a un remoto escarceo de Sancho en la práctica poética sirve de preámbulo para la irrupción de una escena de significativos trazos ideológicos. Ocurre cuando la pareja se topa con un festín en que unos frailes se solazan con unas así llamadas "muchachas alegres de Sevilla". Don Quijote arremete contra los frailes y derriba a uno a quien obliga, bajo pena de muerte, y siguiendo el modelo cervantino, a comparecer ante Dulcinea. El religioso, por pudores éticos, se niega a hacerlo. En este punto amo y escudero hacen las veces de jueces y deciden conducir al infractor al monasterio de donde debía provenir. Al divisarlo, el fraile se desmonta y, para sorpresa del caballero, escapa. El penúltimo capítulo termina con esta imprevista huida y se inicia el apartado final con una secuencia que de alguna manera parece tratar de equilibrar la mala imagen que ha remanecido de los clérigos con otra que eleve su prestigio mediante la exposición de la caridad eclesiástica. Esta disparidad ${ }^{11}$ de cualificaciones - condena y ponderación del clero- es, según veremos, del todo consecuente con las representaciones sociales que al respecto definen los parámetros ideológicos del autor.

\subsection{LA DISTINCIÓNÉTICA: LOS BUENOS Y LOS MALOS CLÉRIGOS}

Los antagónicos efectos entre la incontinencia de los frailes del capítulo LIX y la frugalidad de los religiosos del capítulo final condicen con las inflamadas reflexiones montalvinas acerca de la cuestión clerical expuestas en la diatriba titulada Mercurial eclesiástica. Es sabido que esta obra surgió como respuesta a la prohibición interpuesta por el obispo Ignacio Ordóñez de leer su conjunto de ensayos Los siete tratados, publicados entre 1882 y 1883 , y escritos durante su exilio en Ipiales. En ellos, Juan Montalvo asesta en diversas ocasiones contra las principales deficiencias que atribuye a

\footnotetext{
${ }^{11}$ Respecto del sentido que esta disparidad cobra en el desenlace de la novela y, más general aun, en el pensamiento central de Montalvo, vale remitirnos a otras reflexiones de Van Dijk, a saber: la naturaleza cambiante de los sistemas ideológicos, destacado en nota anterior, y la dimensión no solo social, sino también cognitiva y discursiva de las ideologías.
}

42 | AlPha No50 (JuLIO 2020) PÁGS. 37-49. ISSN 07 16-4254 
los malos eclesiásticos: simonía y disipación. Los vicios son evocados como una falsificación directa del principio de austeridad que debería regirlos, así como lo notician las siguientes invectivas: "Si no ayunaran, se enflaquecieran, se murieran de necesidad. Pero como ayunan, y con más ganas en cuaresma, véanlo ustedes reventando de gordos" (Montalvo, 2006b, p. 29); “(...) el chocolate es contra la pudicicia, será mucho si toman una taza mediana, contraponiendo el casto queso a las propiedades lujuriantes de ese regalo de Satanás" (p. 31).

Si bien es cierto Montalvo confiesa explícitamente su desconfianza y aun su temor por las consecuencias que puedan acarrear los comportamientos sacerdotales ("Yo temo menos la espada o la pistola del enemigo militar que los medios ocultos de los criminales de sotana" (p. 89)), no dejó de serle prioritario hacer constar que su desdén no se dirigía hacia el aparato ideológico en su totalidad, sino estrictamente hacia algunos de sus indignos representantes y hacia quienes impiden la difusión de las ideas, entre ellos el citado obispo de Quito:

No soy enemigo del clero, los fanáticos me infunden miedo, los ignorantes lástima, los perversos odio, los corrompidos desprecio, a Ignacio Ordóñez no lo puedo querer ni estimar, es hombre malo, muy malo, de tristes antecedentes, y, si no hay quien no le vaya a la mano, de turbias esperanzas (Montalvo, 2006b, p. 88).

No pasa inadvertido que en su denuncia de la calidad moral de Ordóñez el autor haya empleado los mismos acentos con que expuso sus ataques contra el dictador Ignacio Veintemilla en las Catilinarias: "El cabo Ordóñez pertenece a la categoría de clérigos flacos, galgos temibles que no se engordan con dos raciones por día, porque los pecados hambrientos que habitan sus entrañas lo devoran todo en perjuicio de su estuche" (Montalvo, 2006b, p. 30). Ordóñez le sirve de epítome para iniciar una condena ideológica y generalizada contra todos los malos representantes del poder eclesiástico. Es así como llega a admitir que para las instancias religiosas su propia figura debía corresponder a la de un blasfemo o un hereje:

Debo ser hereje porque muestro mi indignación contra las brutalidades de los frailes impíos y soberbios, como sucedió una vez en la puerta de una iglesia. Era un fraile llamado Cartagena, ídolo de las viejas, y más de las muchachas, fraile joven y presumido que se peinaba de copete y andaba oliendo a ámbar y agua de Florida. Pero bravo con la gente pobre, casi feroz (p. 92).

Como contraste con estas desviaciones, evoca el ejemplo del cura de Santa Engracia, sacerdote en quien cifra las virtudes teologales de la piedad, solidaridad, caridad, templanza y misericordia, atributos cristianos que, según afirma, los clérigos 
ecuatorianos prohíben. Prueba de ello -razona- es que el obispo Ordóñez vetó la circulación del relato El cura de Santa Engracia.

Como explica Pazos Barrera (Montalvo, 2006a), en la sociedad de la época la hegemonía evangélica predicaba el paternalismo ${ }^{12}$, que convertía a los fieles en seguidores pasivos de la doctrina y sin autodeterminación ${ }^{13}$. De aquí redunda la importancia del sacerdote de Santa Engracia, que reúne en una persona el amor trascendente y la misericordia. Las virtudes del cura no se reducen al encomio de las acciones, sino a su personalidad, que son espejo de aquellas. Respecto de su retrato, Montalvo se detiene precisamente en la limpieza de sus hábitos y la sobriedad: "Vino, jamás: licores fuertes, menos: esos son fracasos de la templanza, buitrones de las virtudes. El tabaco... el tabaco... soporífero infame que entorpece el cerebro, ensucia boca y manos y aplebeya el espíritu (...)" (Montalvo, 2009, p. 63). Ambas cualidades -limpieza y sobriedad-son las que servirán de contraste para la construcción articulada de los personajes religiosos en los dos capítulos finales de su Quijote.

Así como las virtudes del cura de Santa Engracia condensan los méritos de los clérigos que asisten a don Quijote en el capítulo final, la concepción de los curas libertinos que los preceden parece haber sido extraída de esta contundente revelación:

No les toquen la bolsa a los clérigos, porque ahí están la impiedad y la herejía. "Dispongan ustedes del infierno como les parezca, les decía un cura de rompe y rasga a ciertos radicales de Colombia; pero déjenme el purgatorio, porque él me da de comer, que beber y muchacha con quien vivir" (Montalvo, 2006b, p. 91).

El obispo Ordóñez es bandera de estas impropiedades, tanto de manera gráfica como simbólica. Como adelantamos, el acusado veto que el religioso impuso contra los tratados de Montalvo se basó en su descontento contra las denuncias que el escritor dirigió a los vicios de la institución eclesiástica y de cuya lectura llegó a afirmar que no podía "menos que causar grave daño en la honestidad de las costumbres" (Montalvo, 2006b, p. 129).

\footnotetext{
${ }^{12}$ Premisa básica para el asiento moral de la Iglesia como AIE.

${ }^{13}$ Estas reacciones habrían de generar en el espacio colonial y postcolonial una suerte de sentido común cuanto a la supremacía de la Iglesia como AIE. Respecto de este concepto Van Dijk aclara lo siguiente: (...) si se identifica el sentido común con las creencias generales de una cultura, y si las ideologías, como fundamento de creencias de grupo específicas, están basadas en dicho terreno común cultural, las ideologías mismas no son una forma de sentido común (...) a las ideologías se las da mucho menos por sentadas que a las creencias culturales, porque a menudo se las enseña más explícitamente dentro del grupo y son cuestionadas por y, por lo tanto, defendidas, ante otros grupos (Van Dijk, 1999, p. 139).
}

44 | AlPha No50 (Julio 2020) PÁGs. 37-49. ISSN 07 16-4254 
La respuesta del autor no se limitó a la exposición de los deméritos del clero, sino a la transfiguración de los propios artificios doctrinales de la Iglesia para neutralizar la autoridad del obispo en cuestión. En su evocación del infierno, irónica e iracunda, declara que "Si no hubiera infierno común para todos los malos, yo le pediría a Dios un infierno especial para el obispo Ordóñez y sus clérigos" (p.119). El infierno -señala- es una instancia terrenal sin proyección en lo trascendente. Otra flexión simbólica que arguye contra Ordóñez es la embriaguez, que vuelve a darle base para citar una de las principales impertinencias que acusa en el orden clerical: la falta de templanza. Ordóñez no bebe literalmente. Su embriaguez es figurada por cuanto padece de la ebriedad de pasiones como la soberbia, la envidia y la ira. De este modo, la embriaguez etílica funciona como símil de la falta de sobriedad o moderación de los hábitos, vicios que repercuten directamente en la integridad moral de los clérigos que la padecen.

Como adelantamos, no es de extrañar que Ordóñez sea equiparado al objeto de otra de las obsesiones críticas de Montalvo: el dictador Ignacio Veintemilla, concebido en sí mismo como un ARE "No os lamentéis de mi suerte, ecuatorianos; admiraos de la vuestra, de las garras de un facineroso como Ignacio Veintemilla, habéis ido a caer en las de un inquisidor de Felipe II como Ignacio Ordóñez" (p.12). La asociación es tan sustancial que Montalvo llega a entender al obispo como una continuación eclesiástica de los ARE conforme se aprecia en el comentario citado por él mismo a propósito de una advertencia programada por Veintemilla contra los liberales hacia fines de su gestión: "Pero no saben que les he de dejar a Ordóñez" (p.47).

En consecuencia, para Montalvo el obispo de Quito es epítome de la represión contra un pueblo que juzga como críticamente incompetente. Por otra parte, reconoce que la Iglesia ecuatoriana está vinculada al Estado y que los religiosos son, ante todo, ciudadanos con derecho a representación política. Por ello, en virtud de esta facultad y en honor a su calidad de ministros eclesiales, les exige el cumplimiento de la rectitud, la buena fe y la conciencia. Quedan así deslegitimados todos aquellos religiosos que efectúan alianzas con caudillos por intereses de poder.

\subsection{EL TESTAMENTO: REPRESENTACIÓN DEL AIE JURÍDICO}

Este conjunto de cuestionamientos y condenas se revierten, pues, en la figuración de los licenciosos frailes que dominan el penúltimo capítulo del Quijote ecuatoriano. Estando Montalvo, como dijimos, no contra el clero sino contra el mal clero, el episodio final evita que una precipitada acusación de anticlericalismo pueda interferir en la constitución de las representaciones sociales del escritor. 
El capítulo LX se caracteriza por la discontinuidad definitiva de las aventuras - "Por la primera vez en el curso de las aventuras, no quiso Don Quijote seguir adelante (...)" (Montalvo, 2004, p. 497)-. La acción anuncia su fin en un espacio cerrado, un monasterio situado en el campo, entre cuyas funciones está la de cobijar a los caminantes. En él hay un cuarto y "un hermano destinado a cumplir los deberes de la hospitalidad" (p. 497). Como antónimo evidente de los frailes viciosos se introducen religiosos caritativos, piadosos y frugales quienes, en virtud de la moral definida por la orden, carecen de vino para ofrecer. Tras esta recepción sobresale un hecho que inspira a don Quijote la elaboración de su testamento y el consiguiente cierre de los eventos de la ficción: la muerte reciente de un fraile anciano. Con esta decisión se consolidan dos aspectos centrales en la naturaleza del personaje: la afirmación de su catolicismo y la lucidez con que habrá de morir: "Este buen hidalgo experimentaba a menudo grandes conmociones interiores de piedad; aun cuando hubiese muerto loco no habría olvidado las prácticas de los católicos, siendo como era, muy adicto a la religión de sus mayores" (p. 498).

Aun cuando a estas alturas el caballero no ha recuperado la cabalidad de sus facultades, la elaboración del testamento, nos dice el narrador, aspira a ser válida por cuanto fue redactada durante un claro de lucidez ("Sudó poco el hidalgo en su piadosa tarea, como quien tenía buena disposición intelectual y un cierto despejo en sus locuras (...)" (p. 499). No obstante, debido a que la naturaleza de las disposiciones se afinca en la experiencia caballeresca, queda radicalmente anulado el presupuesto de cordura que requisita el acto de testar, conforme lo dicta un AIE jurídico como el notarial. El documento en cuestión fue concebido en verso y, como el de su modelo cervantino, cumple con cuatro ítemes, que a saber son:

$1^{\circ}$ Que no lo lloren plañideras ${ }^{14}$, sino únicamente Dulcinea.

$2^{\circ}$ Que se pongan sus armas sobre su tumba.

$3^{\circ}$ Que se construya una pirámide para su caballo ${ }^{15}$.

$4^{\circ}$ Que se entregue un quinto de su hacienda a Sancho, sin habida cuenta de los salarios adeudados. Lo que reste será para su sobrina ${ }^{16}$.

\footnotetext{
14 "En Latinoamérica, esta costumbre se desarrolló a partir del siglo XVII volviéndose una actividad donde el precio, así como el estatus del difunto, se elevaba dependiendo del número de mujeres contratadas y la intensidad del llanto y los gritos", según noticia la Revista de chilenidad Corral Victoria (Anónimo, 2014).

${ }^{15}$ Esta solicitud habla de su aún elevado grado de locura. De no ser posible una pirámide, determina la erección de una ciudad: “(...) La ciudad de aquella pieza, / La ciudad de Rocinante / Se llamará Rocinecia” (Montalvo, 2004, p. 502)).

${ }^{16}$ Se trata del único ítem ajeno al imaginario caballeresco. 46 | Alpha No50 (JULIO 2020) PÁGS. 37-49. ISSN 07 16-4254
} 
La conclusión del testamento podría haber quedado consagrada como una cita o una rememoración del efectuado por su antecesor, pero Montalvo introduce un personaje inesperado que rompe con dicho eco y regresa de modo concesivo con su arremetida contra la naturaleza de los malos clérigos. Vale mencionar que, antes de su irrupción, la pareja participa de la misa de rigor dejando una duda sutil acerca del motivo de esta decisión: “(...) caballero y escudero salieron a misa, ya de buenos cristianos, ya por no escandalizar con partirse de oílla (...)” (Montalvo, 2004, p. 504). Un fraile bromista, José Modesto, modifica el documento ideado por el caballero añadiéndole un quinto ítem, en el que consta el deseo apócrifo de don Quijote de que si alguien retomara la caballería contratase sin miramiento alguno a Sancho como escudero.

De este modo, el ecuatoriano configura una suerte de espiral (condenaponderación-condena) en torno al problema de los eclesiásticos, que se inicia con la identificación de los frailes réprobos, transita por los religiosos virtuosos y acaba con el clérigo burlón. Con este recurso rotativo, Montalvo da cuenta de que el comportamiento de los sacerdotes es no solo uno de sus ejes temáticos, sino también expresión del entendimiento de la Iglesia como institución ideológica que, al igual que sus paralelos políticos, debiera ceñirse a los parámetros de la integridad moral para la construcción de una sociedad más equilibrada y justa.

\section{CONSIDERACIONES FINALES}

Desde el punto de vista ideológico, en sus Capítulos... Juan Montalvo se demuestra un crítico encumbrado del poder autoritario y de los declives de la moral. Sus críticas no suelen asumir entresijos indirectos o implícitos al modo cervantino, sino todo lo contrario: abunda en cuestionamientos despejados y directos. No obstante, cuando critica al clero su posición se relativiza y adopta un modo menos beligerante. En los capítulos finales de su novela se nos enseñan de manera circular los rasgos que, desde la perspectiva de sus bases axiológicas, corrompen a la Iglesia tanto en su constitución como AIE como en el cuerpo mismo de su doctrina. Junto con la disipación resultante del consumo irresponsable de la bebida y del trato con mujeres de vida ligera coexiste la ponderación de los méritos que deberían regir la vida de un clérigo ejemplar.

Estas representaciones trascienden a la conducción de don Quijote y Sancho como personajes. Desde el inicio de sus Capitulos...y prefigurándose en las declaraciones del Buscapié, se colige que las matrices ideológicas y sus materializaciones en los AIE han sido establecidas en forma a priori, de modo que los personajes de la continuación habrán de operar como meros canales de exposición de dichas representaciones. Por ello, en probablemente inconsciente consonancia con el Quijote de Avellaneda, Montalvo 
transfiere posiciones ideológicas y postulados éticos rígidos sin la mediación relevante de intersticios ideológicos, de lo que resultan personajes narrativos que no evolucionan.

En el desenlace, aun cuando caballero y escudero sinceran su voluntad de retornar a la aldea y elaboran un testamento, el narrador, en lugar de confirmar estos designios, los relativiza con la incorporación de un religioso advenedizo. Dicho de otro modo, no podemos saber lo que habrían hecho don Quijote y Sancho después de añadido el quinto ítem, pero podemos sospechar que en nada habrían cambiado sus conductas y representaciones sociales centrales.

\section{OBRAS CITADAS}

Aguilar Perdomo, María del Rosario (2017). "Cervantes o las fabulaciones americanas del Quijote". Cuadernos del Lectio, N5 5, p. 13-30, janeiro/junio. Consultado en noviembre de 2017. Disponible en:

https://www.academia.edu/33200436/Cervantes_o_las_fabulaciones_americana s_delQuijote

Althusser, Louis (2013). "Ideologia e Aparelhos Ideológicos do Estado (Notas para uma Investigação)”. En Slavoj Žižek, (org.). Um mapa da ideología. Rio de Janeiro: Contraponto ( $5^{\mathrm{a}}$ reimpresión).

Anderson Imbert, Enrique (1957). Historia de la literatura hispanoamericana. México D. F.: Fondo de Cultura Económica.

Clavijo, Jácome (2007). Tras las huellas de Montalvo. Tomo I. Ensayos. Quito: Instituto Iberoamericano de Patrimonio Natural y Cultural. IPANC.

García Astrada, Arturo (1971). América y las ideologías. Córdoba: Universidad Nacional de Córdoba.

González Stephan, Beatriz (1987). La historiografía literaria del liberalismo hispanoamericano del siglo XIX. Ciudad de La Habana: Ediciones Casa de las Américas.

Gutiérrez Trápaga, Daniel (2016). "De los Amadises a los Quijotes: continuación y ciclo en Cervantes y Avellaneda". Revista Historias Fingidas, volumen 4: 137155. Disponible en http://historiasfingidas.dlls.univr.it/index.php/hf. Consultado el 12/04/2017.

Montalvo, Juan (2009). Fisiología de la risa. Quito: Ministerio de Educación. (2006a). Siete Tratados. Edición de José L. Abellán. Madrid: Editora Nacional.

__ (2006b). Mercurial eclesiástica. Ambato: Ediciones Casa de Montalvo. 
_ (2004). Capitulos que se le olvidaron a Cervantes. Edición de Ángel Esteban. Madrid: Cátedra.

Naranjo, Plutarco (2006). Juan Montalvo. Quito: Corporación Editora Nacional.

Riorda, Mario y Farré, Marcela (2012). ¡Ey, las ideologías existen. Comunicación política y campañas electorales en América Latina. Buenos Aires: Biblos.

Roig, Arturo (1995). El pensamiento social de Juan Montalvo. Sus lecciones al pueblo. Quito: Corporación Editora Nacional.

Van Dijk, Teun (1999). Ideología. Un enfoque multidisciplinario. Barcelona: Editorial Gedisa. Žižek, Slavoj (2013). Um mapa da ideologia. Rio de Janeiro: Contraponto. 